\title{
Neuraxial anesthesia for postpartum tubal ligation at an
}

\section{academic medical center [version 1; peer review: 3 approved]}

\author{
Carlos Delgado, Wil Van Cleve, Christopher Kent, Emily Dinges (D), \\ Laurent A. Bollag
}

Department of Anesthesiology \& Pain Medicine, University of Washington, Seattle, Seattle, Washington, 98195, USA

\begin{tabular}{l}
\hline F1 First published: 26 Sep 2018, 7:1557 \\
https://doi.org/10.12688/f1000research.16025.1 \\
Latest published: 26 Sep 2018, 7:1557 \\
https://doi.org/10.12688/f1000research.16025.1 \\
\hline
\end{tabular}

\section{Abstract}

Background: Use of an in situ epidural catheter has been suggested to be efficient to provide anesthesia for postpartum tubal ligation (PPTL). Reported epidural reactivation success rates vary from $74 \%$ to 92\%. Predictors for reactivation failure include poor patient satisfaction with labor analgesia, increased delivery-to-reactivation time and the need for top-ups during labor. Some have suggested that this high failure rate precludes leaving the catheter in situ after delivery for subsequent reactivation attempts. In this study, we sought to evaluate the success rate of neuraxial techniques for PPTL and to determine if predictors of failure can be identified.

Methods: After obtaining IRB approval, a retrospective chart review of patients undergoing PPTL after vaginal delivery from July 2010 to July 2016 was conducted using CPT codes, yielding 93 records for analysis. Demographic, obstetric and anesthetic data (labor analgesia administration, length of epidural catheter in epidural space, top-up requirements, time of catheter reactivation, final anesthetic technique and corresponding doses for spinal and epidural anesthesia) were obtained.

Results: A total of 70 patients received labor neuraxial analgesia. Reactivation was attempted in 33 with a success rate of $66.7 \%$. Patient height, epidural volume of local anesthetic and administered fentanyl dose were lower in the group that failed reactivation. Overall, spinal anesthesia was performed in 60 patients, with a success rate of $80 \%$. Conclusions: Our observed rate of successful postpartum epidural reactivation for tubal ligation was lower than the range reported in the literature. Our success rates for both spinal anesthesia and epidural reactivation for PPTL were lower than the generally accepted rates of successful epidural and spinal anesthesia for cesarean delivery. This gap may reflect a lower level of motivation on behalf of both the patients and anesthesia providers to tolerate "imperfect" neuraxial anesthesia once fetal considerations are removed.

\section{Open Peer Review \\ Approval Status $\checkmark$ \\ 12 \\ 23 \\ version 1 \\ 26 Sep 2018

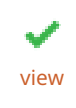 \\ $\checkmark$

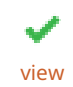 \\ 1. Christine P. McKenzie ID, University of North Carolina Medical Center (UNC Medical Center), Chapel Hill, USA \\ 2. Dana R. Gossett, University of California, San Francisco (UCSF), San Francisco, USA \\ 3. Feyce Peralta (D), Northwestern University, Chicago, USA \\ Any reports and responses or comments on the article can be found at the end of the article.}




\section{Keywords}

obstetrical anesthesia, spinal anesthesia, epidural anesthesia, general anesthesia, tubal sterilization, postpartum period

Corresponding author: Carlos Delgado (delgadou@uw.edu)

Author roles: Delgado C: Conceptualization, Data Curation, Formal Analysis, Methodology, Project Administration, Resources, Software, Supervision, Validation, Visualization, Writing - Original Draft Preparation, Writing - Review \& Editing; Van Cleve W: Formal Analysis, Methodology, Resources, Software, Validation, Visualization, Writing - Original Draft Preparation, Writing - Review \& Editing; Kent C: Conceptualization, Data Curation, Methodology, Resources, Validation, Visualization, Writing - Original Draft Preparation, Writing Review \& Editing; Dinges E: Methodology, Validation, Visualization, Writing - Original Draft Preparation, Writing - Review \& Editing; Bollag LA: Data Curation, Methodology, Resources, Supervision, Validation, Visualization, Writing - Original Draft Preparation, Writing Review \& Editing

Competing interests: No competing interests were disclosed.

Grant information: The author(s) declared that no grants were involved in supporting this work.

Copyright: (c) 2018 Delgado C et al. This is an open access article distributed under the terms of the Creative Commons Attribution License, which permits unrestricted use, distribution, and reproduction in any medium, provided the original work is properly cited. Data associated with the article are available under the terms of the Creative Commons Zero "No rights reserved" data waiver (CC0 1.0 Public domain dedication).

How to cite this article: Delgado C, Van Cleve W, Kent C et al. Neuraxial anesthesia for postpartum tubal ligation at an academic medical center [version 1; peer review: 3 approved] F1000Research 2018, 7:1557 https://doi.org/10.12688/f1000research.16025.1

First published: 26 Sep 2018, 7:1557 https://doi.org/10.12688/f1000research.16025.1 


\section{Introduction}

Tubal ligation in the immediate postpartum period, postpartum tubal ligation (PPTL), is typically performed on the labor ward, but less than $50 \%$ of women that desire PPTL receive the procedure in the immediate postpartum period, despite The American College of Obstetricians and Gynecologists (ACOG) defining PPTL as an urgent procedure due to the limited optimal surgical timeframe ${ }^{1}$. This gap between patient preference and observed outcome emphasizes the importance of an evidence-based anesthetic approach for PPTL to reduce barriers to receiving anesthetic care in the early postpartum period. Use of an existing labor epidural catheter has been proposed as an efficient way to provide anesthesia for PPTL $^{2}$. Older studies reported epidural reactivation success rates varying from $74 \%$ to $92 \%^{2-4}$. Recently, Powell et al. reported an epidural reactivation success rate of $78 \%$ in a prospective observational study of anesthesia for PPTL and outlined the risk factors for failed reactivation of an epidural catheter. Predictors of failure included poor patient satisfaction with labor analgesia, increased deliveryto-reactivation time, and the need for manual top-ups during labor and delivery ${ }^{5}$. Within our practice, and sometimes in the broader obstetric anesthesia community, providers have suggested that rates of failure when attempting catheter "reactivation" for PPTL do not support the practice leaving a labor epidural catheter in place for an interval PPTL. Instead, these providers advocate the routine removal of the epidural catheter followed by a de novo spinal anesthetic (SA). This study evaluated the frequency of success at our center using the aforementioned anesthetic techniques for PPTL and sought to determine if there are clinical success predictors that can aid in anesthetic decision-making.

\section{Methods}

\section{Ethical approval}

This retrospective observational study was approved by the University of Washington Review Board, which waived the requirement of informed consent (HSD Study STUDY0000117). A chart review of all medical records in the labor and delivery unit from July 2010 to July 2016 was conducted to identify patients with CPT codes for bilateral tubal ligation that occurred consecutively after vaginal delivery. No exclusion criteria were applied.

\section{Data collection}

Data collected for each case included demographic data (age, body mass index), obstetric data (gravidity, parity, gestational age achieved) and anesthetic data (type of labor analgesia: combined-spinal epidural or straight lumbar epidural; number of regional anesthesia attempts performed; length of epidural catheter in epidural space, top-up requirements during labor, time of catheter reactivation after delivery, if applicable; and the initial and final anesthetic techniques used to complete the case: successful epidural reactivation, de novo spinal anesthetic or general anesthesia). Perioperative doses for medications for spinal and epidural anesthetics as well as the use of supplemental sedative/hypnotic agents were also collected. Successful epidural reactivation was defined as completion of the surgical procedure under epidural analgesia.
Data analysis

Statistical analysis of collected data was performed using $\mathrm{R}$ version 3.4.3 (R Foundation for Statistical Computing, Vienna, Austria). Univariate distributions are described as proportions, means and standard deviations, or medians and interquartile ranges, as appropriate. Continuous variables were compared using t-tests and ordinal variables were compared using Fisher's exact test. Statistical significance was pre-specified as $p<0.05$.

\section{Results}

Data from 93 patients were analyzed. Neuraxial analgesia for labor was used in 70 patients $(75 \%)$. Of these patients that received labor analgesia, $33(47 \%)$ underwent attempts at reactivation, with a success rate of $66.7 \%$ (22 patients). For this group of patients, the mean documented length of catheter in space was $4.9( \pm 0.3) \mathrm{cm}$. A total of four patients $(18 \%)$ required top-ups during labor. Median time to reactivation after delivery was 4.8 (IQR 3.3-9.8) hours. The mean volume of local anesthetic used to initiate anesthesia for the surgical procedure was $21.7( \pm 7.6) \mathrm{ml}$. The mean epidural fentanyl dose was $86.7( \pm 22.9) \mu \mathrm{g}$. Intravenous midazolam $(1.9 \pm 0.5 \mathrm{mg})$ and fentanyl $(68.2 \pm 35.5 \mu \mathrm{g})$ were also given in 16 patients. When comparing the characteristics of successful and unsuccessful epidural reactivations, we observed that patient height $(163 \pm 7.2 \mathrm{~cm}$ versus $158 \pm 6.0 \mathrm{~cm}, \mathrm{p}=0.03)$, volume of local anesthetic administered during reactivation $(21.7 \pm 7.6 \mathrm{ml}$ versus $14.8 \pm 13.2 \mathrm{ml}, \mathrm{p}=0.03)$, and dose of epidural fentanyl $(86.7$ $\pm 22.9 \mu \mathrm{g}$ versus $63 \pm 24.4 \mathrm{mcg}, \mathrm{p}=0.03$ ) were lower in the group that failed catheter reactivation. Total intravenous fentanyl was also higher $(127.1 \pm 57.6 \mu \mathrm{g})$ in this group compared to the successful group $(68.2 \pm 35.5 \mu \mathrm{g})(\mathrm{p}=0.007)$ (Table 1).

In patients in which reactivation was unsuccessful, a rescue SA was attempted in five cases with a success rate of $80 \%$. The patient that failed SA (bupivacaine $11.2 \mathrm{mg}$, no opioid) had received large amounts of epidural solution at reactivation (30 $\mathrm{ml}$ chloroprocaine $3 \%$ and $10 \mathrm{ml}$ lidocaine 2\%). General anesthesia was the final anesthetic technique for the remaining unsuccessful epidural reactivations and the failed SA.

Epidural reactivation was not attempted in 37 patients $(53 \%)$. There were two cases that received general anesthesia as the primary technique. One patient received combined spinal epidural (CSE) anesthesia as the primary technique due to maternal congenital cardiac disease. SA was performed after removal of epidural catheter in 34 patients. This technique was successful in 25 patients $(74 \%)$. For the cases in which SA block was not achieved, general anesthesia (8 patients) or CSE anesthesia (1 patient) were used.

Single-shot spinal anesthesia in patients with pre-existing epidural catheters (combining those in whom epidural reactivation was and was not attempted) was performed in 39 patients, with an overall success rate of $74 \%$. An attempt to reactivate the catheter prior to spinal placement had been carried out in 4 patients (13.8\%), with a median elapsed time of 3.3 (IQR 0.7-9.6) hours after delivery and an average volume of $12.7 \pm 8.6 \mathrm{ml}$ of 


\begin{tabular}{|c|c|c|c|}
\hline Variables & $\begin{array}{l}\text { Successful } \\
\text { reactivation } \\
(n=22)\end{array}$ & $\begin{array}{l}\text { Failed } \\
\text { reactivation } \\
(n=11)\end{array}$ & $P$ value \\
\hline Age (years) & $31.3 \pm 4.4$ & $30 \pm 3.5$ & 0.21 \\
\hline Height (cm) & $163 \pm 7.2$ & $158 \pm 6.0$ & 0.03 \\
\hline BMI & $33 \pm 6.0$ & $31.4 \pm 5.1$ & 0.24 \\
\hline Gestational age (weeks) & $37.9 \pm 2.4$ & $37.4 \pm 3.0$ & 0.32 \\
\hline $\begin{array}{l}\text { Length of catheter in space } \\
(\mathrm{cm})\end{array}$ & $4.9 \pm 0.4$ & $4.9 \pm 1.0$ & 0.48 \\
\hline $\begin{array}{l}\text { Patients requiring top-ups } \\
\text { during labor }(n, \%)\end{array}$ & $4,18.1 \%$ & $5,45 \%$ & 0.09 \\
\hline $\begin{array}{l}\text { Duration of epidural } \\
\text { analgesia (h), IQR (h) }\end{array}$ & $4.3,2.3-6.7$ & $3.9,1.8-5.4$ & 0.47 \\
\hline $\begin{array}{l}\text { Time to reactivation }(h), \\
\text { IQR }(h)\end{array}$ & $4.8,3.3-9.8$ & $4,1.9-11.2$ & 0.38 \\
\hline $\begin{array}{l}\text { Total epidural local } \\
\text { anesthetic (ml) }\end{array}$ & $21.7 \pm 7.6$ & $14.8 \pm 13.2$ & 0.03 \\
\hline Total epidural fentanyl $(\mu \mathrm{g})$ & $86.7 \pm 22.9$ & $63 \pm 24.4$ & 0.03 \\
\hline Total IV midazolam (mg) & $1.9 \pm 0.5$ & $1.8 \pm 0.3$ & 0.48 \\
\hline Total IV fentanyl (mg) & $68.2 \pm 35.5$ & $127.1 \pm 57.6$ & 0.007 \\
\hline
\end{tabular}

All data presented as mean \pm standard deviation; median, interquartile range; percentage. T-test and Fisher's exact test, $\mathrm{p}<0.05$ for statistical significance. $\mathrm{BMI}$, body mass index; IQR, interquartile range; IV, intravenous.

local anesthetic. Due to insufficient levels of anesthetic blockade after attempt at reactivation, SA was chosen as the rescue anesthetic technique. The mean volume of local anesthetic (hyperbaric bupivacaine $0.75 \%$ ) was $1.5 \pm 0.3 \mathrm{ml}$. The mean intrathecal fentanyl dose was $14.2 \pm 6.4 \mu \mathrm{g}$.

Data regarding demographic, obstetric and anesthetic variables comparing successful versus unsuccessful SA in patients with a pre-existing epidural catheter is presented in Table 2. Apart from a more advanced gestational age in the failed SA group, no statistical differences existed between successful and unsuccessful SAs.

Of the 23 patients who did not have a pre-existing epidural catheter at the time of PPTL, $21(91 \%)$ received a single-shot spinal block, with a success rate of $91 \%$. The remaining two cases were performed under general anesthetic and with CSE as initial technique. The mean volume of local anesthetic (hyperbaric bupivacaine $0.75 \%$ ) was $1.5 \pm 0.2 \mathrm{ml}$. The mean intrathecal fentanyl dose was $15.2 \pm 6.8 \mu \mathrm{g}$. Intravenous midazolam (mean 2.1 $\pm 0.9 \mathrm{mg}$ ) and fentanyl (mean $87.5 \pm 59.4 \mu \mathrm{g}$ ) were also given as adjuvants. No statistical analysis was performed to compare success at performing SA in patients without pre-existing epidurals given the high success rate of this technique.

A review of all cases of attempts at SA (patients with a prior epidural catheter, irrespective of attempts at reactivation, and patients without a pre-existing epidural catheter) revealed a spinal block success rate of $80 \%$ (48 of 60 cases). Mean intrathecal doses were $1.5 \pm 0.2 \mathrm{ml}$ of hyperbaric bupivacaine $0.75 \%$ and $14.2 \pm 6.2 \mu \mathrm{g}$ of fentanyl. Intrathecal fentanyl doses above $20 \mu \mathrm{g}$ added to bupivacaine were associated with spinal failure $(p=0.001)$. No other demographic, obstetric or anesthetic factors were statistically different (Table 3 ).

The final distribution of anesthetic technique and success used for the PPTL is presented in Figure 1.

Dataset 1. Complete data on demographics and the treatment given to each patient surrounding postpartum tubal ligation, including details on treatment method and the pharmaceuticals used (with dose)

https://dx.doi.org/10.5256/f1000research.16025.d218466

Also included is a guide to the abbreviations used.

\section{Discussion}

In a review of 6 years of data from our practice, we observed a success rate of $67 \%$ when attempting to use in situ epidural catheters for PPTL, lower than we expected given the published literature on this topic. A recent retrospective review $(n=202)$ of PPTL anesthesia reported an epidural reactivation success rate of $74 \%$. A prospective study $(\mathrm{n}=100)$ designed to assess the risk factors for failed epidural reactivation reported a success rate of $78 \%$. In analyzing our data, we found no association 
Table 2. Demographic, obstetric and anesthetic data in patients with a preexisting epidural catheter in which spinal anesthesia (SA) was attempted for postpartum tubal ligation.

\begin{tabular}{|c|c|c|c|}
\hline Variable & $\begin{array}{l}\text { Successful SA } \\
(n=29)\end{array}$ & $\begin{array}{l}\text { Failed SA } \\
(n=10)\end{array}$ & $P$ value \\
\hline Age (years) & $32.2 \pm 4.7$ & $32.7 \pm 5.5$ & 0.39 \\
\hline Height (cm) & $165 \pm 8.2$ & $163 \pm 6.8$ & 0.25 \\
\hline BMI & $30.8 \pm 4.6$ & $30.7 \pm 7.6$ & 0.48 \\
\hline Gestational age (weeks) & $36 \pm 4.1$ & $39 \pm 0.7$ & 0.02 \\
\hline Length of catheter in space $(\mathrm{cm})$ & $4.9 \pm 0.6$ & $4.6 \pm 0.4$ & 0.11 \\
\hline $\begin{array}{l}\text { Patients requiring top-ups during } \\
\text { labor }(n, \%)\end{array}$ & $13,45 \%$ & $3,33 \%$ & 0.41 \\
\hline $\begin{array}{l}\text { Duration of epidural analgesia } \\
\text { (h), IQR (h) }\end{array}$ & $5.5,2.4-8.4$ & $2.6,1.3-8.5$ & 0.44 \\
\hline $\begin{array}{l}\text { Epidural reactivation attempted } \\
(\mathrm{n}, \%)\end{array}$ & $4,13.8 \%$ & $1,10 \%$ & 0.75 \\
\hline Time to reactivation (h), IQR (h) & $3.3,0.7-9.6$ & $12.8^{*}$ & NA \\
\hline $\begin{array}{l}\text { Total epidural local anesthetic } \\
\text { (ml) }\end{array}$ & $12.7 \pm 8.6$ & $40^{*}$ & NA \\
\hline $\begin{array}{l}\text { Total intrathecal local anesthetic } \\
(\mathrm{ml})\end{array}$ & $1.5 \pm 0.3$ & $1.5 \pm 0.2$ & 0.27 \\
\hline Total intrathecal fentanyl $(\mu \mathrm{g})$ & $14.2 \pm 6.4$ & $18 \pm 7.6$ & 0.12 \\
\hline Total IV midazolam (mg) & $1.9 \pm 0.6$ & $2.3 \pm 2.1$ & 0.24 \\
\hline Total IV fentanyl (mg) & $96 \pm 59.2$ & $120.7 \pm 52.6$ & 0.16 \\
\hline
\end{tabular}

All data presented as mean \pm standard deviation; median, interquartile range; percentage. T-test and Fisher's exact test, $p<0.05$ for statistical significance. *Only one patient in this group underwent reactivation. No statistical calculations were performed. $\mathrm{BMI}$, body mass index; IQR, interquartile range; IV, intravenous; NA, not applicable.

Table 3. Demographic, obstetric and anesthetic data in patients in which spinal anesthesia (SA) was attempted for postpartum tubal liugation (overall).

\begin{tabular}{|l|l|l|l|}
\hline Variable & $\begin{array}{l}\text { Successful SA } \\
(\mathbf{n = 4 8})\end{array}$ & $\begin{array}{l}\text { Failed SA } \\
(\mathbf{n = 1 2})\end{array}$ & P value \\
\hline Age (years) & $32.5 \pm 5.0$ & $32.5 \pm 5.8$ & 0.47 \\
\hline Height $(\mathrm{cm})$ & $164 \pm 7.0$ & $162 \pm 6.7$ & 0.29 \\
\hline BMl & $30.4 \pm 4.1$ & $30.3 \pm 7.3$ & 0.47 \\
\hline Gestational age (weeks) & $37 \pm 3.6$ & $39 \pm 0.7$ & 0.05 \\
\hline History of epidural catheter placement $(\mathrm{n}, \%)$ & $29,60 \%$ & $10,83 \%$ & 0.13 \\
\hline Total intrathecal local anesthetic $(\mathrm{ml})$ & $1.5 \pm 0.2$ & $1.5 \pm 0.2$ & 0.32 \\
\hline Total intrathecal fentanyl $(\mu \mathrm{g})$ & $14.2 \pm 6.2$ & $20 \pm 6.5$ & 0.01 \\
\hline
\end{tabular}

All data presented as mean \pm standard deviation; median; percentage. T-test and Fisher's exact test, $p<0.05$ for statistical significance. BMI, body mass index.

between previously noted risk factors and epidural failure. Vincent et al. reported that a shorter time interval between delivery and reactivation attempt was a predictor for success, with reinjection within 4 hours of delivery having the highest success rate $^{3}$. These findings are in agreement with data from the recent prospective study by Powell et al..$^{5}$. Others have suggested that the time interval between catheter insertion and reactivation is of importance, with a period less than 24 hours as a more reliable predictor of success compared to time between delivery and reactivation ${ }^{6}$. Our findings do not reveal any relationship between time of catheter placement or delivery and success of reactivation. The majority of catheters were reactivated within 5 hours of delivery, while only one was used more than 12 hours after delivery. 


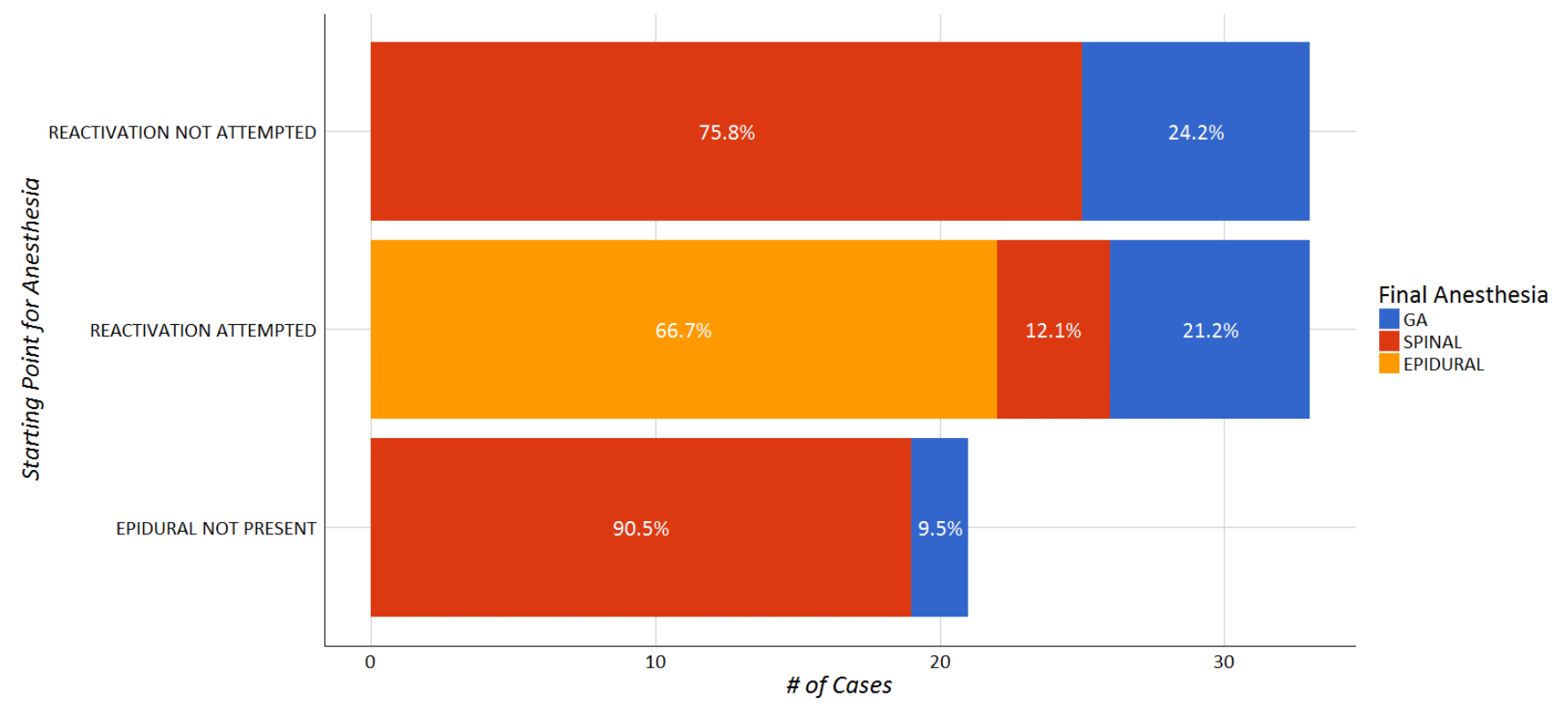

Figure 1. Distribution of final anesthetic technique for postpartum tubal ligation in relation to success of the initial technique.

The immediate postpartum period is the ideal time to perform PPTL due to the ease and convenience for both physicians and patients $^{1}$. In fact, this procedure is defined by ACOG as an urgent procedure, because failure to accomplish the procedure during the same hospitalization as delivery may make the procedure more complex and increase the risk of unintended pregnancy in the first year following birth ${ }^{7,8}$. The availability of nursing, anesthesia, and obstetric staff for this procedure alongside busy workloads on the labor ward may contribute to failures in achieving a pre-discharge PPTL.

The probability of pain during surgery has been linked with the height of the patient under epidural anesthesia, but only in very short and tall patients, and it significantly interacts with weight ${ }^{9}$. Although we observed that the mean height in the group that failed reactivation was lower (close to $5 \mathrm{~cm}$ ), we struggle to find a biological plausibility to this finding. Administration of higher volumes of epidural solution increases dermatomal spread, particularly with bolus administration ${ }^{10}$. The group in which reactivation was unsuccessful received a lower volume of both local anesthetic and opioid. Epidural medication is typically incrementally titrated during catheter reactivation. If, early during the reactivation attempt, an inadequate or patchy block is noted, epidural reactivation is typically aborted to avoid a potentially high rescue SA. This could potentially explain the lower volume of local anesthetic used in that group. While an increased use of fentanyl in the failed epidural reactivation group is observed, this corresponds to the total dose, which includes cases with conversion to general anesthesia.

For those without preexisting epidural analgesia, the successful use of spinal anesthesia with hyperbaric bupivacaine with or without opioids has been reported by multiple authors ${ }^{11,12}$. This technique was favored by most providers for patients who had labored without neuraxial analgesia with a high rate of success. Administration of a dose of local anesthetic similar to that used for cesarean deliveries (e.g. $12 \mathrm{mg}$ of bupivacaine) seems to provide sufficient anesthesia for PPTL ${ }^{12,13}$.

When spinal anesthesia was attempted in patients with a history of epidural analgesia during labor, however, our success rate was found to be only $80 \%$. This is a higher rate than the reported 2-6\% range of failure described for spinal anesthesia for cesarean delivery ${ }^{14,15}$ and clearly higher than the $1 \%$ conversion rate of regional to general anesthesia due to failed spinal anesthesia, as recommended by the Royal College of Anesthetists $^{16}$. Spinal anesthesia failure was three times higher in women where an epidural was used but not topped up for emergent cesarean delivery in a large retrospective audit of over 5000 cesarean deliveries ${ }^{15}$. Clear free flowing cerebrospinal fluid (CSF) is associated with a successful spinal block. Prior injection of local anesthetic into the epidural space could lead providers to mistake epidural local anesthetic return through a spinal needle for CSF, which might provide an explanation for failure to achieve SA after epidural analgesia had been performed ${ }^{17}$.

Some evidence points to a need in increasing doses of local anesthetic used in SA for PPTL to adjust for changes in segmental blockade requirements in the postpartum ${ }^{18}$. Huffnagle et al. found that while $7.5 \mathrm{mg}$ of hyperbaric bupivacaine provided adequate surgical anesthesia for this procedure, some failed spinals occurred at this dose ${ }^{19}$. The mean local anesthetic doses used in our institution were similar to our standard for cesarean deliveries (1.4 $\mathrm{ml}$ of hyperbaric bupivacaine $0.75 \%$ ), and we did not find a difference between successful and failed SAs in our patients. We also found that advanced gestational age was linked to failure 
of SA, whether there had been any epidural space manipulation. Our finding contrasts with reports of inadequate surgical anesthesia for cesarean deliveries in pre-term parturients, even though it was determined that low fetal weight was the main factor implicated ${ }^{20}$. Notably, fentanyl doses above $20 \mu \mathrm{g}$ were observed overall in the spinal failure group, without being associated to a decrease in corresponding local anesthetic dosage.

Conversion to general anesthesia in the obstetric patient after neuraxial anesthesia placement is often the result of decreased patient tolerance to pain during the procedure, in addition to concerns by the surgical team, as reported by a large retrospective review of over 35,000 spinal anesthetics for cesarean delivery by Guglielmo et al. In this study, SA was impossible to perform in a few rare cases. More commonly, the block was achieved but was insufficient to provide adequate surgical block ${ }^{21}$. General anesthesia was used in 55\% of cases of PPTL in small community hospitals according to the Obstetric Anesthesia Workforce Survey; this contrasts with the use of general anesthesia in less than $25 \%$ of the cases of PPTL in large-center referral center hospitals affiliated with university programs ${ }^{22}$. Ultimately, the decision to use a particular type of anesthetic for PPTL should be individualized based on obstetric and anesthetic factors, as well as taking into account patient preference. Regional anesthesia, however, seems to be the favored approach, as the time for maternal physiology to return baseline in the postpartum period is not well delineated ${ }^{23}$.

There are several limitations to our study. As a singleinstitution retrospective study with small numbers of patients in the subgroups of interest and relatively few procedures, we can simply add to the existing studies on this topic with limited generalizability. Further, even though each record was personally reviewed by one of the authors (all of whom are members of the obstetric anesthesia division) to minimize the amount of missed data and erroneous coding regarding type of anesthesia, our data collection is potentially subject to bias due to anesthetic technique preferences on the part of the research team. Documentation of the reasons for favoring attempts at reactivation over proceeding with spinal anesthesia directly was not consistently found in the clinical records. In most of the cases in which reactivation was not attempted despite the presence of an epidural catheter that functioned well during labor and was left in situ, no rationale for this decision could be found in the medical records. Provider preference could have been guided by either a distrust of a catheter that has not been infused for some time or lack of patience or time available to reactivate the catheter to achieve adequate surgical anesthesia. Prior provider experience with failed epidurals might also have played a part. Some have recommended spinal anesthesia even in parturients with indwelling epidural catheters to avoid less-than-perfect epidural reactivation rates and minimize time delays and costs ${ }^{4}$. In fact, in a published survey of BTL practices in academic institutions, up to $40 \%$ of respondents elect not to leave a catheter in situ to be used after delivery ${ }^{6}$. Our study is obviously not powered to evaluate complication rates associated with the different anesthetic techniques used for PPTL. One of the largest studies of PPTL found very low rates of complications of any type and, notably, $86 \%$ of the procedures in this series were done with general anesthesia ${ }^{24}$.

In summary, our study found lower success rates for epidural reactivation for PPTL than those reported in the literature. There was also a lower success rate for spinal anesthetics placed after an epidural catheter was used to provide labor analgesia. We were unable to find clinical predictors for the failure rate. The need for conversion to general anesthesia, besides being attributed to an insufficient block, may reflect a lower level of motivation on behalf of both the patients and anesthesia providers to tolerate suboptimal anesthesia when fetal considerations are no longer a factor and some aspects of maternal physiology are already less concerning for the use of general anesthesia.

\section{Data availability}

Dataset 1. Complete data on demographics and the treatment given to each patient surrounding postpartum tubal ligation, including details on treatment method and the pharmaceuticals used (with dose). Also included is a guide to the abbreviations used. DOI: https://doi.org/10.5256/ f1000research.16025.d218466 25 .

\section{Grant information}

The author(s) declared that no grants were involved in supporting this work.

\section{Acknowledgements}

This work was presented as an abstract at the 2017 49th Annual meeting of the Society for Obstetric Anesthesia and Perinatology (SOAP) in Bellevue, WA, USA.
1. Committee on Health Care for Underserved Women: Committee opinion no. 530: access to postpartum sterilization. Obstet Gynecol. 2012; 120(1): 212-5. PubMed Abstract | Publisher Full Text

2. Goodman EJ, Dumas SD: The rate of successful reactivation of labor epidural catheters for postpartum tubal ligation surgery. Reg Anesth Pain Med. 1998; 23(3): 258-61.

PubMed Abstract | Publisher Full Text

3. Vincent RD Jr, Reid RW: Epidural anesthesia for postpartum tubal ligation using epidural catheters placed during labor. J Clin Anesth. 1993; 5(4): 289-91. PubMed Abstract | Publisher Full Text
4. Viscomi CM, Rathmell JP: Labor epidural catheter reactivation or spina anesthesia for delayed postpartum tubal ligation: a cost comparison. $J$ Clin Anesth. 1995; 7(5): 380-3.

PubMed Abstract | Publisher Full Text

5. Powell MF, Wellons DD, Tran SF, et al:: Risk factors for failed reactivation of a labor epidural for postpartum tubal ligation: a prospective, observational study. J Clin Anesth. 2016; 35: 221-4. PubMed Abstract | Publisher Full Text

6. McKenzie C, Akdagli S, Abir G, et al.: Postpartum tubal ligation: A retrospective review of anesthetic management at a single institution and a practice survey 
of academic institutions. J Clin Anesth. 2017; 43: 39-46. PubMed Abstract | Publisher Full Text

7. Richardson MG, Hall SJ, Zuckerwise LC: Postpartum Tubal Sterilization: Making the Case for Urgency. Anesth Analg. 2018; 126(4): 1225-31.

PubMed Abstract | Publisher Full Text

8. Thurman AR, Janecek T: One-year follow-up of women with unfulfilled postpartum sterilization requests. Obstet Gynecol. 2010; 116(5): 1071-7. PubMed Abstract | Publisher Full Text

9. Curatolo M, Orlando A, Zbinden AM, et al:: A multifactorial analysis to explain inadequate surgical analgesia after extradural block. Br J Anaesth. 1995; 75(3) 274-81.

PubMed Abstract | Publisher Full Text

10. Hogan Q: Distribution of solution in the epidural space: examination by cryomicrotome section. Reg Anesth Pain Med. 2002; 27(2): 150-6. PubMed Abstract | Publisher Full Text

11. Huffnagle SL, Norris MC, Huffnagle HJ, et al.: Intrathecal hyperbaric bupivacaine dose response in postpartum tubal ligation patients. Reg Anesth Pain Med. 2002; 27(3): 284-8

PubMed Abstract | Publisher Full Text

12. Habib AS, Muir HA, White WD, et al.: Intrathecal morphine for analgesia after postpartum bilateral tubal ligation. Anesth Analg. 2005; 100(1): 239-43. PubMed Abstract | Publisher Full Text

13. Teoh WH, Ithnin F, Sia AT: Comparison of an equal-dose spinal anesthetic for cesarean section and for post partum tubal ligation. Int J Obstet Anesth. 2008; 17(3): 228-32.

PubMed Abstract | Publisher Full Text

14. Pan PH, Bogard TD, Owen MD: Incidence and characteristics of failures in obstetric neuraxial analgesia and anesthesia: a retrospective analysis of 19,259 deliveries. Int J Obstet Anesth. 2004; 13(4): 227-33. PubMed Abstract | Publisher Full Text

15. Kinsella SM: $\mathbf{A}$ prospective audit of regional anaesthesia failure in $\mathbf{5 0 8 0}$ Caesarean sections. Anaesthesia. 2008; 63(8): 822-32. PubMed Abstract | Publisher Full Text

16. Russell IF: Technique of anaesthesia for caesarean section. Raising the Standards: A Compendium of Audit Recipes. 2006; 166-7.
17. Einhorn LM, Habib AS: Evaluation of failed and high blocks associated with spinal anesthesia for Cesarean delivery following inadequate labour epidural: a retrospective cohort study. Can J Anaesth. 2016; 63(10): 1170-8. PubMed Abstract | Publisher Full Text

18. Abouleish El: Postpartum tubal ligation requires more bupivacaine for spinal anesthesia than does cesarean section. Anesth Analg. 1986; 65(8): 897-900. PubMed Abstract

19. Huffnagle SL, Norris MC, Leighton BL, et al:: Do patient variables influence the subarachnoid spread of hyperbaric lidocaine in the postpartum patient? Reg Anesth. 1994; 19(5): 330-4 PubMed Abstract

20. Adesope OA, Einhorn LM, Olufolabi AJ, et al:: The impact of gestational age and fetal weight on the risk of failure of spinal anesthesia for cesarean delivery. Int J Obstet Anesth. 2016; 26: 8-14.

PubMed Abstract | Publisher Full Text

21. Guglielmo L, Pignataro A, Di Fiore G, et al: Conversion of spinal anesthesia into general anesthesia: an evaluation of more than 35,000 spinal anesthetics. Minerva Anestesiol. 2010; 76(9): 714-9. PubMed Abstract

22. Traynor AJ, Aragon M, Ghosh D, et al:: Obstetric Anesthesia Workforce Survey: A 30-Year Update. Anesth Analg. 2016; 122(6): 1939-46. PubMed Abstract | Publisher Full Text

23. Practice Guidelines for Obstetric Anesthesia: An Updated Report by the American Society of Anesthesiologists Task Force on Obstetric Anesthesia and the Society for Obstetric Anesthesia and Perinatology. Anesthesiology. 2016; 124(2): 270-300. PubMed Abstract | Publisher Full Text

24. Huber AW, Mueller MD, Ghezzi F, et al.: Tubal sterilization: complications of laparoscopy and minilaparotomy. Eur J Obstet Gynecol Reprod Biol. 2007; 134(1): 105-9. PubMed Abstract | Publisher Full Text

25. Delgado C, Van Cleve W, Kent C, et al.: Dataset 1 in: Neuraxial anesthesia for postpartum tubal ligation at an academic medical center. F1000Research. postpart 2018 . http://www.doi.org/10.5256/f1000research.16025.d218466 


\section{Open Peer Review}

\section{Current Peer Review Status:}

\section{Version 1}

Reviewer Report 04 February 2019

https://doi.org/10.5256/f1000research.17502.r40801

(C) 2019 Peralta F. This is an open access peer review report distributed under the terms of the Creative Commons Attribution License, which permits unrestricted use, distribution, and reproduction in any medium, provided the original work is properly cited.

\section{Feyce Peralta}

Department of Anesthesiology, Feinberg School of Medicine, Northwestern University, Chicago, IL, USA

General comments: Relevant topic for obstetricians and obstetric anesthesiologists with key public health implications. Authors evaluated success rate of different neuraxial techniques for PPTL. Retrospective study using small dataset from a single institution.

Introduction: "Tubal ligation in the immediate postpartum period, postpartum tubal ligation (PPTL), is typically performed on the labor ward, but less than $50 \%$ of women that desire PPTL receive the procedure in the immediate postpartum period, despite The American College of Obstetricians and Gynecologists (ACOG) defining PPTL as an urgent procedure due to the limited optimal surgical timeframe1." I suggest placing reference number 8 (Thurman) before current reference number 1 (Committee opinion no. 530). Consider splitting this sentence in two.

Methods: Retrospective study of patients that underwent PPTL after vaginal delivery over a 6-year period at a single institution.

I recommend expanding the definition of successful epidural catheter reactivation (e.g., completion of PPTL under epidural anesthesia with same epidural catheter previously used for labor analgesia and delivery).

The authors should clarify who performed the chart review. 1 investigator? 2 investigators?

The authors could include a pregnancy risk stratification (low vs. high risk) as part of their demographic data. Albanese et al. $\left(2017^{1}\right)$ reported on the request and fulfilment of PPTL according to pregnancy risk. Anesthetic practices are likely to be affected by this variable.

Results: The authors analyzed data from a very small number of patients. Overall, this section is very easy to read and to follow. 
Discussion: The greatest limitation of this study is the small sample size. Therefore, conclusions cannot be made based on this study regarding predictors for the success of neuraxial anesthesia for PPTL. Future directions could be added to the discussion section.

The authors should consider moving the second and third sentences to the introduction section.

\section{References}

1. Albanese A, French M, Gossett DR: Request and fulfillment of postpartum tubal ligation in patients after high-risk pregnancy.Contraception. 2017; 95 (3): 234-238 PubMed Abstract |

Publisher Full Text

Is the work clearly and accurately presented and does it cite the current literature? Yes

Is the study design appropriate and is the work technically sound?

Yes

Are sufficient details of methods and analysis provided to allow replication by others? Yes

If applicable, is the statistical analysis and its interpretation appropriate? Yes

Are all the source data underlying the results available to ensure full reproducibility? Yes

Are the conclusions drawn adequately supported by the results?

Yes

Competing Interests: No competing interests were disclosed.

Reviewer Expertise: Obstetric anesthesiologist

I confirm that I have read this submission and believe that I have an appropriate level of expertise to confirm that it is of an acceptable scientific standard.

Reviewer Report 12 December 2018

https://doi.org/10.5256/f1000research.17502.r40803

(C) 2018 Gossett D. This is an open access peer review report distributed under the terms of the Creative Commons Attribution License, which permits unrestricted use, distribution, and reproduction in any medium, provided the original work is properly cited. 


\section{Dana R. Gossett}

Department of Obstetrics, Gynecology and Reproductive Sciences, University of California, San Francisco (UCSF), San Francisco, CA, USA

\section{General comments:}

This is a topic of interest to obstetric anesthesiologists and obstetricians, and highlights the role of obstetric anesthesiologists in providing access to a needed service that often goes unprovided (postpartum tubal ligation-PPTL). The authors examine success rates of pre-existing labor epidurals for surgical anesthesia for tubal ligation.

\section{Study design:}

This is a retrospective study of undergoing postpartum tubal ligation at a single institution over a 6 year period. Method of labor analgesia and method of anesthesia for the PPTL were collected, and rate of successful re-use of the labor epidural for the PPTL was calculated.

\section{Abstract:}

The abstract provides an accurate synopsis of the paper's design and findings.

\section{Introduction:}

Overall the introduction is quite short, but does provide appropriate background and citations. Do the authors have a citation to support the statements "Within our practice, and sometimes in the broader obstetric anesthesia community, providers have suggested that rates of failure when attempting catheter "reactivation" for PPTL do not support the practice leaving a labor epidural catheter in place for an interval PPTL. Instead, these providers advocate the routine removal of the epidural catheter followed by a de novo spinal anesthetic (SA)"?

\section{Materials \& Methods:}

This is a retrospective review of all women undergoing PPTL over a 6 year period. Data were collected regarding demographic and obstetric factors, anesthetic method and dosing, and factors previously identified as predictors of failure of epidural "reactivation" after delivery.

\section{Results, Tables/Figures:}

In general, the results are clearly communicated. During the study period, only 93 women undergo PPTL, 70 of whom have labor epidurals. Of these, only 33 actually have an attempt to reactivate the epidural for use during the PPTL-this then represents the target population, a very small number. Of these, $67 \%$ had successful reactivation of their epidurals.

For women who received spinal anesthesia (SA) to complete their PPTL, fewer had successful SA if they'd had a prior epidural (74\% successful spinal vs $91 \%$ of those who had not had a labor epidural.)

\section{Discussion:}


The discussion section is very long in proportion to the remainder of this paper and could be substantially trimmed. Paragraph 2 could be moved to the introduction/background.

While the authors state that previously published predictors of epidural re-activation were not confirmed in this study, they are underpowered to evaluate some. For example, the number of patients requiring "top ups" (redoses of the epidural) was 9, with 4 in the successful reactivation group and 5 in the failed group-for rates of $18 \%$ and $45 \%$. Because of small numbers, the $p$-value for this comparison is 0.09 , but it is likely that it would reach statistical significance with greater numbers.

One of the most significant limitations, as acknowledged by the authors, is the lack of information about why/how decisions were made by the anesthesiologists about whether or not to use an existing epidural, and what to use next or instead. This introduces the potential for selection bias of subjects having re-activation attempts.

It would be ideal if the authors concluded their discussion by tying their findings back to the larger question they are investigating-can they make any recommendations about what the optimal method would be? Or, as their study may not provide this, what type of investigation would they recommend to get to that answer?

\section{Summary:}

This retrospective study of anesthetic use for PPTL demonstrated a lower rate of successful reactivation of labor epidurals than previous reports. There is no clear explanation of this unanticipated finding.

A prospective trial would better address this by removing clinician bias/practice patterns from the decision-making about anesthetic mode, and limiting differences (known and unknown) between the two groups of patients. Given the infrequency of PPTL, a multicenter trial would be required to accrue patients in a reasonable amount of time, so the choice of a retrospective review is understandable.

Is the work clearly and accurately presented and does it cite the current literature? Yes

Is the study design appropriate and is the work technically sound? Partly

Are sufficient details of methods and analysis provided to allow replication by others? Yes

If applicable, is the statistical analysis and its interpretation appropriate? Yes

Are all the source data underlying the results available to ensure full reproducibility? No source data required

Are the conclusions drawn adequately supported by the results? 
Yes

Competing Interests: No competing interests were disclosed.

Reviewer Expertise: Obstetric care, operative obstetrics, evidence-based practice

I confirm that I have read this submission and believe that I have an appropriate level of expertise to confirm that it is of an acceptable scientific standard.

Reviewer Report 18 October 2018

https://doi.org/10.5256/f1000research.17502.r38781

(C) 2018 McKenzie C. This is an open access peer review report distributed under the terms of the Creative Commons Attribution License, which permits unrestricted use, distribution, and reproduction in any medium, provided the original work is properly cited.

\section{Christine P. McKenzie}

Department of Anesthesiology, University of North Carolina Medical Center (UNC Medical Center), Chapel Hill, NC, USA

The article presents a small retrospective review of anesthetic management for postpartum tubal ligations. The article is well-written and organized. The data are presented clearly and concisely.

The author outlines limitations of the study such as a small number of patients and generalizability. However, it adds to the current literature on PPTL and higher than expected neuraxial anesthesia failure rates. There are no identified predictors for success/failure of epidural reactivation; however, given the low numbers the study is underpowered to access predictors.

The article discusses the clinical considerations for anesthetic management and the importance of completing these urgent PPTL procedures.

Is the work clearly and accurately presented and does it cite the current literature? Yes

Is the study design appropriate and is the work technically sound?

Yes

Are sufficient details of methods and analysis provided to allow replication by others? Yes

If applicable, is the statistical analysis and its interpretation appropriate? Yes

Are all the source data underlying the results available to ensure full reproducibility? Yes 
Are the conclusions drawn adequately supported by the results?

Yes

Competing Interests: No competing interests were disclosed.

I confirm that I have read this submission and believe that I have an appropriate level of expertise to confirm that it is of an acceptable scientific standard.

The benefits of publishing with F1000Research:

- Your article is published within days, with no editorial bias

- You can publish traditional articles, null/negative results, case reports, data notes and more

- The peer review process is transparent and collaborative

- Your article is indexed in PubMed after passing peer review

- Dedicated customer support at every stage

For pre-submission enquiries, contact research@f1000.com 